\title{
CERTIFICADO SUCESORIO EUROPEO. ALGUNAS IDEAS PRELIMINARES
}

\author{
EUROPEAN CERTIFICATE OF SUCCESSION. PRELIMINARY IDEAS
}

\author{
María Elena Cobas Cobiella \\ Universidad de Valencia. España/Spain \\ m.elena.cobas@uv
}

"Después de todo, la muerte es sólo un síntoma de que hubo vida"

Mario Benedetti

Recibido/Received: 30/01/2015

Aceptado/Accepted: 27/04/2015

\section{RESUMEN}

El presente trabajo tiene como finalidad adentrar al lector en algunas ideas preliminares sobre el Certificado Sucesorio Europeo, su concepto, naturaleza jurídica y los caracteres más destacados, resaltando el papel del notariado en esta nueva era de modernización e internacionalización.

\section{PALABRAS CLAVE}

Sucesión mortis causa, sucesiones transfronterizas, certificado sucesorio europeo, notarios.

\section{SUMARIO}

I. Introducción. II. Internacionalización y modernización del notariado español. III. Notas preliminares sobre el certificado sucesorio europeo. 1. Marco legislativo actual en materia de certificado sucesorio europeo. 2. Ventajas y finalidad del certificado sucesorio europeo. 2.1. Ventajas. 2.2. Finalidad del certificado sucesorio europeo. 3. Concepto y naturaleza jurídica del certificado sucesorio europeo. 3.1 Concepto del certificado sucesorio europeo. 3.2 Naturaleza jurídica del Certificado Sucesorio europeo. 4. Contenido del certificado sucesorio europeo. 5. Algunos caracteres del certificado sucesorio europeo. IV. Concluyendo estas notas. V. Bibliografía.

\section{ABSTRACT}

This paper aims to introduce the reader to some preliminary ideas on the European Succession Certificate, its concept, legal nature and the most outstanding characters, highlighting the role of notaries in this new era of modernization and internationalization.

\section{KEYWORDS}

Succession mortis causa, border successions, European Certificate of Succession, notaries.

\section{CONTENTS}

I. Introduction. II. Internationalization and modernization of Spanish notary. III. Preliminary notes on the European certificate of succession. 1. Current legislative framework in relation to the European succession certificate. 2. Advantages and purpose of the European succession certificate. 2.1. Advantages. 2.2. Purpose of the European succession certificate. 3. Concept and legal nature of the European succession certificate. 3.1. Concept of European succession certificate. 3.2 Legal nature of European succession certificate. 4. Content of the European succession certificate. 5. Some characters of the European succession certificate. IV. Concluding these notes. References. 


\section{INTRODUCCIÓN}

La muerte es un hecho natural y jurídico inexorable, y ello conlleva la necesidad de organización del patrimonio de las personas, convertido en herencia, una vez que ha fallecido, siguiendo lo que señala Royo Martínez: "Los romanos dijeron que las cosas pro domino suo claman (claman por su dueño). Cierto, pero aún más cierto que para servir a los hombres las cosas claman por un dueño cuando la muerte arrebata a quien lo era" (Royo Martínez, 1951: 3).

La inmigración y la emigración, como dos fenómenos íntimamente relacionados, han llevado a la aparición de un nuevo y peculiar panorama internacional con la creciente aparición de numerosas sucesiones internacionales que adquieren una relevancia cualitativa; hecho que requiere un replanteamiento y un nuevo enfoque que se adapte a las necesidades del tráfico jurídico actual que permita, a su vez, cierta agilidad, prontitud y decoro en la tramitación de las sucesiones mortis causa transfronterizas. En este contexto aparece el Certificado Sucesorio Europeo.

El nacimiento de este documento comunitario ha tenido algunos antecedentes que amerita señalar, por un lado los cambios sociales, económicos y políticos, que han dado lugar a flujos cada vez más crecientes de inmigración, y por otra parte la aprobación de varios instrumentos jurídicos de peso, que han ido remodelando el camino hasta la aprobación de una normativa coherente y unificadora. Reto nada fácil para el Derecho.

En el marco normativo cabe destacar como mínimo, siendo precedente y referencia obligatoria, la redacción del Étude de droit comparé sur les règles de conflits de jurisdictions et de conflits de lois relatives aux testaments et successionis dans les États membres de l'Union Européenne, publicado en el año 2004 por el Instituto Notarial Alemán, el cual agrupa las principales problemáticas en torno a la regulación de las sucesiones a nivel europeo, así como y en segundo lugar, el Libro Verde sobre sucesiones y testamentos, presentado el 1 de marzo de 2005 que abrió el debate a consulta sobre cuestiones de trascendencia como ley aplicable y la prueba de la condición de heredero, finalmente, en tercer lugar hay que hacer mención a la Propuesta de Reglamento del Parlamento Europeo y del Consejo relativo a la competencia, la ley aplicable, el reconocimiento y la ejecución de resoluciones y los actos auténticos en materia de sucesiones y a la creación del certificado sucesorio europeo, presentado en fecha 14 de octubre de 2009.

En cuanto al marco social, huelgan las explicaciones en este sentido, sin embargo conviene destacar que las estadísticas en la materia hablan por sí solas en relación al fenómeno de la inmigración, en la Unión Europea residen dieciocho millones y medio de personas que no poseen la nacionalidad de un Estado miembro, más de cinco millones de personas nacionales de un Estado miembro de la Unión Europea reside habitualmente en otro Estado miembro distinto, asimismo existen más de tres millones de inmuebles situados en Estados miembros que son propiedad de personas que no residen en dicho Estado miembro y finalmente más de 800.000 ciudadanos alemanes son propietarios de bienes inmuebles en España, Italia y Francia (Iglesias, 2008: 337-364).

A ello se une la naturaleza de la inmigración, que abarca desde la emigración de las personas desde el sur de Europa a países del norte durante la segunda mitad del siglo XX, las migraciones hacia Europa provenientes de Asia y África, los movimientos de trabajadores del Este de Europa hacia la Europa occidental, el turismo de los pensionistas (Carrascosa, 2014: 6) y otras modalidades que habría que añadir, como las recientes salidas de profesionales jóvenes (caso España) hacia otros países de Europa. Todo ello ha revolucionado la tradicional sucesión mortis causa. 
En este contexto se aprueba en fecha 27 de julio de 2012 (Diario Oficial de la Unión Europea) el Reglamento $n^{\circ}$ 650/2012 del Parlamento Europeo y del Consejo, de 4 de julio de 2012, relativo a la competencia, la ley aplicable, el reconocimiento de los documentos públicos en materia de sucesiones mortis causa y la creación de un certificado sucesorio europeo. Cuya mayor virtud es que unifica las reglas del Derecho Internacional privado en sede de sucesión mortis causa, "en una materia tradicionalmente impregnada de divergencias y particularismos nacionales", y da lugar a la aparición de una especialización sucesoria (Chirock, 2014: 122-123).

Más recientemente se ha publicado en fecha 9 de diciembre de 2014, el Reglamento (UE), número 1329/2014 (Disposición en vacatio legis, LCEur 2014\2336.

Ambas normas constituyen un paso más en la construcción de un Derecho Europeo unificado, que en el ámbito del Derecho de Sucesiones había sido prácticamente impensable, por la propia naturaleza de esta disciplina, y por la coexistencia histórica entre dos sistemas sucesorios, romano y germano, que a pesar de que parece un tema estrictamente doctrinal e histórico, tiene una vital influencia para la comprensión y aplicación de las sucesiones mortis causa, las categorías jurídicas, extensible a las fases que integran la constitución del derecho hereditario, afectando desde la apertura hasta la adquisición de la herencia, culminando así el proceso hereditario.

\section{INTERNACIONALIZACIÓN Y MODERNIZACIÓN DEL NOTARIADO ESPAÑOL. NOTARIADOS Y CERTIFICADO SUCESORIO EUROPEO}

La función notarial no se muestra ajena a estos movimientos tectónicos, y convulsos de los nuevos tiempos, de ahí que ha ido en evolución, manteniendo sus profundas raíces civilistas e históricas, a la par que se adapta al nuevo marco y construcción de un Derecho europeo unificado, las razones para esta adaptación, pueden ser muchas y variadas, aunque casi me atrevería a apostar, que una razón de peso, está en la necesidad de supervivencia de la institución por un lado, por otro, -no menos importante- por los embates que ha ido recibiendo de otros sectores de la práctica profesional, y finalmente por los profundas transformaciones de la sociedad, lo que denomina algún sector de la doctrina como sociedad líquida del siglo XXI (Carrascosa, 2014: 6), que se caracteriza al decir del citado autor, por relaciones humanas y familiares flexibles, breves, provisionales y frágiles, lo que conlleva a que en el siglo XXI, las familias se deshacen con rapidez, las personas encuentran nuevas parejas y cambian de país de residencia con facilidad: "el fresh start familiar está de moda", en correspondencia con la idea de la modernidad líquida que desarrolla por su parte Bauman, (2000: 157-166), que destaca la sociedad actual como víctima de la rapidez acelerada de los cambios técnicos, sociales y económicos.

Estos cambios que aunque pueden parecer imperceptibles, a los ojos de los neófitos en la materia, están presentes y son de interés, porque el Notariado ostenta un papel decisivo en la construcción del documento público, a lo que hay que añadir que este nuevo contexto, está marcado por un cambio radical en el ejercicio de muchas profesiones, por la presencia de los nuevos espacios de circulación, libertad, seguridad y justicia, representados por el "tan polémico en la actualidad Espacio Schengen", que ha posibilitado libertad en el ámbito comunitario para la libre circulación de personas, y que son manifestaciones de las políticas europeas cuyo objetivo final, es promover la integración real de los ciudadanos europeos, 
potenciando el desarrollo social, económico y cultural, con vistas a crear una verdadera ciudadanía europea (Flamini et al, 2014: 1700).

Esta nueva etapa hace que el quehacer y la función notarial sean vistos desde dos perspectivas, la internacionalización y la modernización de ésta. En lo que respecta a modernización de la fe pública, quizás lo más adecuado o acertado sería en vez de hablar de modernización de la función notarial, debería hablarse con más propiedad de una modernización de la justicia, y dentro de este contexto está el Notario, quien este nuevo entorno económico, social, y legislativo se ha visto abocado a asumir nuevos retos en razón del entorno nacional, el comunitario y la propia inmigración, de ahí que en la actualidad esté presente la función notarial en todas las propuestas de reformas en materia de jurisdicción voluntaria que adjudicarán al Notario dentro de sus funciones la de divorciar y autorizar matrimonios, (Cobas, 2012: 167) o la actual pasión de algunos Notarios por la mediación como fórmula de resolución extrajudicial de conflictos.

La internacionalización del Notario se vincula más, con la extensión de sus funciones a un contexto más europeo y menos nacional, ocupándose de temas que tienen que ver con la prevención en la lucha por actos delictivos vinculados con el blanqueo de capitales, problemáticas, que generalmente escapan del propio contorno del territorio español, o más recientemente, y aunque vinculado con la persona, los derechos derivados de la sucesión de una sucesión mortis causa, cuando se trate de sucesiones con repercusión transfronteriza; a tenor del artículo 64 del Reglamento, que establece la competencia para expedir el Certificado Sucesorio europeo, en primer lugar a los tribunales tal como lo define el artículo 3 , apartado 2, y en segundo lugar designa como otra autoridad expedidora, a la que sea competente para sustanciar sucesiones mortis causa, lo que deja el camino expedito para que los notarios sean unos de los funcionarios o autoridades que ostenten la citada competencia para expedir el correspondiente certificado.

\section{NOTAS PRELIMINARES SOBRE EL CERTIFICADO SUCESORIO EUROPEO}

\section{Marco legislativo actual en materia de Certificado Sucesorio Europeo}

En fecha 27 de julio de 2012 el Diario Oficial de la Unión Europea publicaba el Reglamento $n^{\circ}$ 650/2012 del Parlamento Europeo y del Consejo, de 4 de julio de 2012, relativo a la competencia, la ley aplicable, el reconocimiento de los documentos públicos en materia de sucesiones mortis causa y la creación de un Certificado Sucesorio Europeo, tal como se hizo referencia anteriormente. Más recientemente se ha publicado en fecha 9 de diciembre de 2014, el Reglamento (UE), número 1329/2014 (Disposición en vacatio legis, LCEur 2014\2336), que establece los formularios mencionados en el Reglamento (UE), número 650/2012 (LCEur 2012\1030), del Parlamento Europeo y del Consejo relativo a la competencia, la ley aplicable, el reconocimiento y la ejecución de las resoluciones, a la aceptación y la ejecución de los documentos públicos en materia de sucesiones mortis causa y a la creación de un certificado europeo sucesorio (DOL 16 diciembre 2014, nº 359, p. 30).

La importancia de esta normativa tal como nos dice Prats Albentosa, se encuentra en que hace posible que los ciudadanos puedan preparar por anticipado su sucesión mortis causa, y garantizar eficazmente los derechos de los sucesores, bien sean herederos o legatarios, así como el derecho de los acreedores (Prats, 2012: 38), lo que se ratifica en el Considerando 7, del Reglamento (UE) número 650/2012, de 4 de julio, al señala la conveniencia de facilitar el buen funcionamiento del mercado interior suprimiendo los obstáculos a la libre circulación 
de aquellas personas que actualmente encuentran dificultades a la hora de ejercer sus derechos sucesorios con repercusiones transfronterizas.

Esta normativa sucesoria tiene como objetivo crear una herramienta jurídica, que permita la circulación de efectivos (capital mobiliario) y otros activos, en la búsqueda de armonización de las normas de derecho sustantivo (Flamini et al, 2014: 1702).

\section{Ventajas y finalidad del Certificado Sucesorio Europeo}

\subsection{Ventajas del Certificado Sucesorio Europeo}

Las ventajas que tiene el Certificado Sucesorio Europeo son amplias, destaco las siguientes: en primer lugar agilizará las operaciones sucesorias y dentro de ellas, particionales y las adjudicaciones de herencia, llegado el caso, tal como advierte (Espiñeira Soto, 2010: 3), como Estado plurilegislativo, siempre que se cuente con un fiable Registro Europeo de Actos de Última Voluntad y con una campaña de concienciación a los ciudadanos de la importancia: primero de manifestar la voluntad y segundo de hacerlo mediante disposiciones mortis causa otorgadas en forma auténtica. En segundo orden de cosas armonizará las sucesiones en el ámbito europeo, porque la sucesión de una persona puede verse sujeta a normativas recogidas en diversos ordenamientos jurídicos, lo que conlleva sin lugar a dudas a dificultades para acceder a la tramitación de la herencia, a costes económicos elevados, tiempo entre otros, lo que puede evitarse con la centralización en un documento como el Certificado Sucesorio Europeo.

El Certificado además, ofrece un enfoque de universalidad, de unidad y de armonización en las sucesiones mortis causa, que nace del carácter europeo del citado documento, "a new European authentic deed" (Devaux, 2012, Carrascosa, 2014: 39), que apunta acertadamente "que el legislador de la Unión Europea ha optado por dar carta de nacimiento a un documento sucesorio de carácter europeo, cuyo contenido y cuyo nivel de control jurídico de los extremos que contiene son iguales en todos los Estados miembros. Al uniformizarse el documento sucesorio principal en todos los Estados miembros participantes en el Reglamento 650/2012, todos los particulares disponen de los mismos recursos documentales y todos los Estados miembros participantes pueden emitir ese documento sucesorio, que presenta un contenido uniforme y una igual profundidad de control jurídico sobre el fondo".

Más ventajas pueden extraerse de lo previsto en el Considerando 15 del Reglamento, que prevé la adaptación de un derecho real desconocido al derecho real equivalente más cercano del Derecho de ese otro Estado miembro, y con ello, se incita y propugna además al estudio y a la comprensión de la ley extranjera, porque a fin de determinar el derecho real equivalente más cercano del Derecho nacional, se podrá entrar en contacto con las autoridades o personas competentes del Estado cuya ley se haya aplicado a la sucesión, con vistas a obtener más información sobre la naturaleza y los efectos de ese derecho, incluso se podrá recurrir a las redes ya existentes en el ámbito de la cooperación judicial en materia civil y mercantil, o cualquier otro medio disponible. Esta adaptación de derechos reales desconocidos, deberá entrar con lo previsto en las legislaciones nacionales, en cuanto a la creación de nuevos derechos reales (numerus apertus), frente a la imposibilidad de crear derechos reales atípicos (numerus clausus), tema debatido doctrinalmente y sobre lo que se pronuncia el Reglamento en los Considerandos 18 y 19 respectivamente.

\subsection{Finalidad del Certificado Sucesorio europeo}

El Certificado Sucesorio europeo tiene como finalidad de acuerdo a lo que regula el artículo 63 del Reglamento 650/2012, la de ser utilizado por los herederos, los legatarios que 
tengan derechos directos en la herencia y ejecutores testamentarios o administradores de la herencia que necesiten invocar, en otro Estado miembro, su cualidad de tales o ejercer sus derechos como herederos o legatarios, o bien sus facultades como ejecutores testamentarios o administradores de la herencia.

La segunda finalidad es probatoria de determinados extremos: la cualidad de heredero y /o derechos de los herederos y demás sucesores, la atribución de bienes y las facultades del ejecutor testamentario.

\section{Concepto y Naturaleza jurídica del Certificado Sucesorio Europeo}

\subsection{Concepto}

Las indefiniciones en relación a la definición son muchas, porque no existe unanimidad doctrinal, ni tampoco el Reglamento 650/2012 aclara la cuestión. Para algunos autores estamos en presencia de un documento oficial que acredita la cualidad de heredero, legatario, ejecutor testamentario o administrador de la herencia (Carrascosa, 2014: 37), mientras otro sector cuando hace referencia al documento, lo define como documento público (Espiñeira, 2010: 3), en igual sentido (Calvo, 2014: 2). No se puede olvidar, y es sabido que las definiciones en derecho son complejas, no obstante ello, y tomando partido, apuesto por la nota de documento público, teniendo en cuenta el contenido, la finalidad y las autoridades competentes para hacerlo, siguiendo el texto del Reglamento, aunque soy consciente de que la ausencia de una posición más concreta en este sentido por parte de la normativa en la materia, trae causa en la situación individual de cada país en materia de competencia internacional, el ejercicio de funciones no jurisdiccionales por parte de los que tramitan en muchos países las sucesiones, como puede ser el caso de los Notarios, entre otros muchos motivos.

A pesar de que el Reglamento no se pronuncia sobre el carácter de documento público de Certificado Sucesorio europeo y niega expresamente su condición de título ejecutivo, nos parece que en el marco de la Unión Europea que tiende al reconocimiento mutuo de resoluciones judiciales, a la supresión del exequátur y, en definitiva, a la libre circulación también de documentos, no se puede sino atribuirle la condición de documento público. Para ello, como es evidente, es necesario que sea emitido por una autoridad con competencia para realizar documentos públicos. Además pensamos que proviniendo de un notario o de un juez debería reconocérsele ejecutividad, es decir la condición de título ejecutivo.

Dejémosle de todas formas, algún beneficio de la duda a los lectores y al tiempo que irá delimitando la figura y su empleo en el ámbito europeo.

\subsection{Naturaleza jurídica del Certificado Sucesorio Europeo}

La reciente aparición del Certificado Sucesorio europeo no facilita tampoco el debate en torno a la naturaleza jurídica de éste. En principio, la redacción del Reglamento es expresa en cuanto al valor y eficacia del documento, así en el Considerando 71, se establece que el Certificado Sucesorio europeo debe surtir los mismos efectos en todos los Estados miembros, y que no debe ser un título de fuerza ejecutiva por sí mismo, pero si tiene que tener efecto probatorio, sujeto a una presunción de veracidad, validada esta presunción en el artículo 69. 2 del Reglamento 650/2012, en referencia a la acreditación de la ley aplicable a la sucesión o con cualquier otra ley aplicable a extremos concretos de la herencia, presumiendo que la persona que figure en el certificado como heredero, legatario, ejecutor testamentario o administrador de la herencia tiene la cualidad indicada en él o es titular de los derechos o de las facultades que se expresen sin más condiciones o limitaciones que las mencionadas en el certificado. Y más aún, en el propio artículo 69. 5 se regula que el citado documento será un 
título válido para la inscripción de la adquisición hereditaria. En palabras de (Carrascosa, 2014: 40), "en consecuencia, el Certificado Sucesorio Europeo despliega un muy relevante "efecto de legitimación dominical" frente a terceros. En dicho sentido, la propiedad que el individuo que adquiere del sujeto que figura como heredero en el Certificado Sucesorio Europeo deviene una propiedad blindada, inatacable e irreivindicable incluso por el sujeto originaria y automáticamente propietario del bien".

Hasta ahí parece bastante claro, pero la cuestión se complejiza en relación a si el Certificado Sucesorio europeo tiene la naturaleza de documento público o no. Los criterios en este sentido difieren por parte de la doctrina en la materia, por un lado y en consonancia con lo expuesto anteriormente, algún sector de la doctrina (fundamentalmente los notarios) considera que el Certificado Europeo Sucesorio es un documento público, así expresa su opinión Espiñeira (2010: 3): "los lectores no deben olvidar que el Certificado sucesorio europeo es documento público, emana de Autoridad Pública y como tal documento público, es máquina quitanieves", y que la presunción de veracidad, de corrección, es propia de los documentos públicos que autorizan los notarios, particularmente de las escrituras públicas, se refiere a la autenticidad "de fondo", al contenido del documento, lo que entiende como lógico, porque el Certificado es emitido por Autoridad pública que controla la legalidad. Apoya la tesis de documento público (Calvo: 2014: 2), que destaca que a pesar de la confrontación con las otras fórmulas documentales que el Reglamento define (las resoluciones, las transacciones judiciales y los documentos públicos), de su carácter estrictamente europeo, de la encomienda de su expedición a las autoridades nacionales y de la doble actividad que su tramitación supone, el certificado sucesorio europeo se define como un documento público, estrictamente europeo.

A contrario sensu, otro sector entiende que estamos en presencia de un documento de carácter particular, porque no es una resolución judicial, y tampoco es un documento público con fuerza ejecutiva, ni una transacción judicial y se inclinan por entenderlo como "una nueva especie en el mundo de los títulos jurídicos con efectos extraterritoriales en el Derecho internacional privado europeo" (Rodríguez Sánchez, 2013: 249-260, Carrascosa, 2014: 40), de ahí que el Certificado Sucesorio europeo no puede ser objeto de ejecución, ni de reconocimiento.

Efectivamente, el Reglamento no le concede al Certificado Sucesorio Europeo fuerza ejecutiva, sin embargo habrá que en cualquier caso tener en cuenta lo previsto en el artículo 1216 del Código Civil, cuando integra dentro de los documentos públicos a los autorizados por un Notario y la clasificación de la Ley de Enjuiciamiento Civil, que en el artículo 317.2 considera documentos públicos a los autorizados por notario con arreglo a derecho, sin embargo la doctrina notarial clásica entiende que no todos los documentos que autoriza el Notario son instrumentos públicos, y dice Giménez Arnau: "aunque el Notario actúe profesionalmente, como tal Notario, no siempre el documento o documentos que suscribe al realizar sus funciones son instrumentos públicos", (Giménez Arnau, 1964: 322), pero esta referencia es a documentos administrativos que autoriza como parte de su función y no les alcanza el beneficio del instrumento público, por tanto no creo que sea factible de aplicar al Certificado Sucesorio europeo, que por otra lado constituye un documento con suficiente eficacia jurídica, para no ser tomado en cuenta.

Cuestión que no debe pasar desapercibida, sobre todo si tenemos en cuenta el valor y eficacia que ostenta el citado Certificado. En cualquier caso, estas son algunas ideas preliminares, que el tiempo irá ratificando o desmontando, en dependencia del desarrollo práctico y de la puesta en escena del Certificado Sucesorio a nivel europeo. 


\section{Contenido del Certificado Sucesorio Europeo}

Dos notas identifican el Reglamento 650/2012, marcando la trayectoria jurídica del Certificado Sucesorio europeo en cuanto a su contenido, si nos atenemos a lo previsto en los Considerandos 9 y 10 del Reglamento respectivamente.

En el Considerando 9 se especifica el contenido estrictamente sucesorio de aplicación del mismo, en el Considerando 10 se excluye del Reglamento las cuestiones fiscales y administrativas de Derecho Público, desviando al Derecho nacional todo lo concerniente a los tributos, y especifica concretamente que es competencia del Derecho nacional determinar si la entrega de bienes sucesorios a los beneficiarios en virtud del Reglamento o la inscripción de los bienes sucesorios en un registro pueden estar sujetas a tributación. También se excluyen las cuestiones relativas a la creación, administración y disolución de trust (Considerando 13), y los bienes, derechos y acciones creados o transmitidos por otros medios distintos a la sucesión, es decir otras modalidades de disposición inter vivos (Considerando 14).

Estas exclusiones ratifican el contenido sucesorio de la norma; cuestión que se reafirma en el Considerando 11, que excluye del ámbito de aplicación del Reglamento incluso a materias del Derecho civil distintas a la sucesión mortis causa, incluso algunas de las cuales podrían considerarse que tienen un vínculo con la materia sucesoria, que aunque no se especifican concretamente podrían estar referidas a algunos temas de derechos de familia. No obstante, dado que el cónyuge viudo es sucesor en algunas legislaciones, o en otras concurre en su cuota vidual usufructuaria y que ello, guarda relación directa con los regímenes económicos matrimoniales y condiciona la sucesión, el Reglamento en el artículo 68 ofrece cierto margen de amplitud al contemplar la información relativa a las capitulaciones matrimoniales celebradas por el causante o, en su caso, al contrato celebrado por el causante en el contexto de una relación que conforme a la ley aplicable surta efectos similares al matrimonio e información relativa al régimen económico matrimonial o equivalente.

En cuanto al contenido del Certificado Sucesorio europeo, el Reglamento se decanta por determinados extremos que son definitorios de su alcance y de la entidad que va a tener este documento en los años venideros, regulados en el artículo 68.

\section{Algunos caracteres del Certificado Sucesorio europeo}

Los caracteres del Certificado Sucesorio europeo se consignan a continuación, son aquellas notas que destacan el documento de otros documentos afines.

En primer lugar su carácter internacional y transnacional, de acuerdo a lo previsto en el artículo 62 del Reglamento regula que el certificado se expedirá para ser utilizado en otro Estado miembro, sin necesidad de ningún procedimiento especial, apuntado por lo que regula el artículo 69, también ostenta carácter europeo que se establece en el artículo 62 del Reglamento, tal como señala la doctrina en la materia (Calvo, 2013: 2) y que se entiende como otro carácter del Certificado. Otra nota la constituye el carácter restringido por su aplicación estrictamente en el ámbito sucesorio a tenor de lo que regula el artículo 68 del Reglamento 650/2012 y el Considerando 9; así como la voluntariedad que se confirma como otro de los caracteres, de acuerdo a lo que previene el artículo 62.2 del Reglamento, que declara la no obligatoriedad del Certificado Sucesorio europeo. Ello supone que las personas con derecho a solicitar un certificado no deben estar obligadas a ello, sino tener libertad para recurrir a los demás instrumentos que el presente Reglamento pone a su disposición (resoluciones, documentos públicos o transacciones judiciales). No obstante, ninguna autoridad o persona ante la que se presente un certificado expedido en otro Estado miembro 
debe estar facultada para pedir en lugar del certificado la presentación de una resolución, de un documento público o de una transacción judicial.

La función probatoria del Certificado Sucesorio europeo también se incardina dentro de sus caracteres, ya que el mismo debe surtir los mismos efectos en todos los Estados miembros, de ahí que no se le reconozca condición de título con fuerza ejecutiva por sí mismo pero debe tener efecto probatorio y se ha de presumir que demuestra de manera fidedigna elementos que han quedado acreditados de conformidad con la ley aplicable a la sucesión o con cualquier otra ley aplicable a elementos específicos, tales como la validez material de las disposiciones mortis causa.

El valor probatorio del certificado no debe afectar a los elementos que no se rigen por el presente Reglamento, como la cuestión de la filiación o la determinación de si un bien pertenecía al causante o no.

Otro carácter que reviste el Certificado Sucesorio europeo, lo constituye la presunción de validez, durante su período de validez, el certificado gozará en todos los Estados miembros de la presunción de veracidad, tratándose de una presunción iuris tantum, de ahí que se da por supuesto, salvo prueba en contrario, que la persona designada como heredero, legatario, ejecutor testamentario o administrador es titular del derecho sucesorio o de los poderes. Este apartado se asemeja bastante al parágrafo 2365 del BGB alemán que dice del Erbschein "se presume que el derecho a heredar indicado en el certificado sucesorio corresponde a quien aparece como heredero en el certificado sucesorio y que no está limitado por más disposiciones que las que se indican".

El Certificado Sucesorio europeo es subsidiario porque no sustituye a los documentos que puedan existir con efectos similares en los Estados miembros, de ahí que se mantiene el valor de los documentos nacionales, ya que no se considera como un certificado superior a los nacionales. Este carácter ha sido fruto de un lento trabajo y de maduración, porque la intención no era crear un instrumento europeo que, primando sobre los nacionales y elaborado sobre unas bases que podrían haber resultado frágiles por haberse unificado de forma artificial en el seno de la Unión, no fuera respetuoso con los usos locales de cada Estado, (Chassaing, 2009: 2).

Finalmente no requiere procedimiento especial para su utilización, a tenor del artículo 69 del Reglamento 650/2012, de 4 de julio.

\section{CONCLUYENDO ESTA NOTAS}

La reciente novedad del tema lo hace particularmente complejo de desarrollar, porque sólo el tiempo, la práctica jurídica y el estudio doctrinal de la materia, irán perfilando el tratamiento de las sucesiones internacionales y a la par, como un binomio inseparable, del Certificado Sucesorio europeo.

En cualquier caso del trabajo se desprenden algunas consideraciones que interesa destacar:

No existe en la normativa una solución en relación al concepto y naturaleza jurídica del Certificado Sucesorio europeo, se ha de estar al desarrollo doctrinal y a la práctica jurídica. No obstante los escenarios doctrinales se mueven en dos grandes tendencias, una que lo aprecian como un documento europeo de naturaleza especial y otra tendencia, que se acerca a la consideración de documento con naturaleza pública, en consonancia con el órgano o la autoridad que lo emite. 
La falta de concreción en este sentido hace que si bien el Reglamento señale la carencia de fuerza ejecutiva del Certificado Sucesorio europeo, por otra, le reconocen una presunción de validez, y eficacia importantes, que legitiman determinados extremos, como la cualidad de heredero, la atribución de bienes, el nombramiento de ejecutores testamentarios y otros elementos que integran el contenido del citado documento; nada despreciables para la tramitación de la sucesión mortis causa.

Finalmente cabe señalar que nos parece que en el marco de la modernización de la justicia, de la flexibilización, de la integración europea que parece primar el ámbito del tratamiento de las sucesiones transfronterizas, y que se encaminan finalmente al reconocimiento mutuo de resoluciones, y en definitiva a la libre circulación de los documentos, debería ganar más peso como título ejecutivo.

\section{BIBLIOGRAFÍA}

ÁVILA ÁlVAREZ, P. (1982). Estudios de Derecho Notarial. Madrid: Montecorvo.

BAUMAN, Z. (2000). Modernidad líquida. Buenos Aires: Fondo de Cultura Económica.

CALVO VIDAL. I. A. (2014). "La competencia notarial en el Reglamento (UE) 650/2012, sobre sucesiones". Revista 54, Academia Matritense del Notariado, p. 2.

CARRASCOSA GONZÁLEZ, J. (2014). "Reglamento Sucesorio Europeo y Actividad Notarial". Cuadernos de Transnacional. Marzo, vol. 6, $\mathrm{n}^{\circ}$ 1, pp. 5-44.

CHASSAING, P. (2009). "El certificado sucesorio europeo". El Notario del Siglo XXI. Septiembreoctubre, $n^{\circ} 27$, p. 2.

CHIKOC BARRESA, N. (2014). "Reflexiones sobre los regímenes especiales en el Derecho Internacional Privado Sucesorio según el Reglamento Europeo 650/2012 de 4 de julio de 2012". Cuadernos de Transnacional. Marzo, vol. 6. No 1, pp. 122- 123.

COBAS COBIELLA, M. E. (2012). "Jurisdicción voluntaria y modernización de la justicia: algunos apuntes sobre el tema". Revista Aranzadi de Derecho Patrimonial, n² 29, p 167.

ESPIÑEIRA SOTO, I. (2010). "Efectos del certificado sucesorio europeo: una reflexión". http://www.notariosyregistradores.com/UNIONEUROPEA/ARTICULOS/certificado-sucesorio.htm.

FLAMINI A y LAROCCA, S. (2014). "El Certificado Sucesorio Europeo: una perspectiva unificadora”, en F. Lledó Yagüe y A. Vicandi Martínez (dirs.) El Patrimonio Sucesorio. Reflexiones para un debate reformista. Tomo II. Madrid: Dykinson, Consejo General del Notariado, p. 1700.

GIMÉNEZ-ARNAU, E. (1964). Derecho Notarial Español. Vol. I. Pamplona: Universidad de Navarra, pp. 320-321.

IGLESIAS BUHIGUES, J. L. (2008). "Desarrollo del Espacio Europeo de Justicia: hacia el nuevo D. I Privado de sucesiones en la UE", Curso de Derecho Internacional y Relaciones Internacionales. Vitoria- Gastéiz, pp. 337-364.

PRATS ALBENTOSA, L. (2012). "La sucesión en Europa y el Certificado sucesorio europeo". Escritura Pública, $\mathrm{n}^{\circ} 77$, p. 38.

RODRÍGUEZ SÁNCHEZ, J. S. (2013). "Una introducción al Reglamento de Sucesiones de la UE (desde la perspectiva de los derechos reales sobre bienes inmuebles y el Registro de la Propiedad en España)". Cuadernos de Derecho Registral. Madrid: Editorial Colegio de Registradores de la Propiedad y Mercantiles en España, pp. 249-260.

ROYO MARTÍNEZ, M. (1951). Derecho sucesorio mortis causa. Sevilla: Edelce. 


\section{Breve currículo:}

\section{María Elena Cobas Cobiella}

Profesora Contratada Doctora de la Universidad de Valencia, España. Licenciada en Derecho por la Universidad de la Habana en 1983. Profesora de la Facultad de Derecho, Departamento Civil, Universidad de la Habana, Cuba (1983-1999).Catedrática de Derecho Civil, Facultad de Derecho, Universidad de la Habana, Cuba (1996). Notario Público en Cuba (1992-1998). Doctora en Derecho Civil por la Universidad de Valencia. España (2001). 